\title{
PENGARUH GAYA KEPEMIMPINAN TRANSFORMASIONAL DAN DISIPLIN KERJA TERHADAP KINERJA PERANGKAT DESA DI KECAMATAN MADUKARA KABUPATEN BANJARNEGARA
}

\author{
Yudhistira Pradhipta Aryoko', ${ }^{1}$ Purnadi ${ }^{2}$, Akhmad Darmawan $^{3}$ \\ Fakultas Ekonomi dan Bisnis, Universitas Muhammadiyah Purwokerto

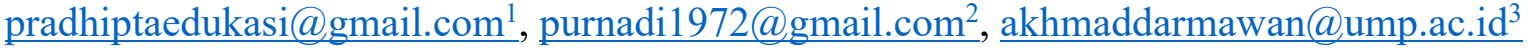

\begin{abstract}
ABSTRAK
Tujuan dari penelitian ini adalah untuk mengetahui pengaruh variabel gaya kepemimpinan transformasional dan disiplin kerja terhadap kinerja perangkat desa. Penelitian ini menggunakan metode studi kasus yang dilakukan terhadap perangkat desa di Kecamatan Madukara, Kabupaten Banjarnegara. Kuesioner dibagikan kepada 173 orang perangkat desa. Hasil dari penelitian ini memiliki sejumlah saran terutama untuk para perangkat desa khususnya di Kecamatan Madukara Kabupaten Banjarnegara, agar lebih meningkatkan kinerjanya supaya sistem pemerintahan desa tersselenggara dengan baik. Teknik analisis data yang digunakan adalah Uji Analisis Regresi Linier Berganda. Hasil penelitian menunjukan bahwa variabel Gaya Kepemimpinan Transformasional (X1) berpengaruh secara signifikan terhadap variabel Kinerja (Y). Kemudian variabel Disiplin Kerja (X2) berpengaruh secara signifikan terhadap variabel kinerja. Variabel Gaya Kepemimpinan Transformasional dan Disiplin Kerja berpengaruh secara simultan terhadap variabel Kinerja. Adapun variable Disiplin Kerja merupakan variabel yang paling mempengaruhi kinerja perangkat desa pada Kecamatan Madukara, Kabupaten Banjarnegara.
\end{abstract}

Kata kunci: Kepemimpinan Transformasional, Disiplin Kerja, Kinerja

\begin{abstract}
The purpose of the study is to determine the influence of variables of transformational leadership style and working discipline towards the performance of village devices. This research uses a case study method conducted against the village device in Madukara Sub-district, Banjarnegara district. Questionnaires were distributed to 173 village device people. The result of this research has a number of advices for village officials, especially in Madukara sub-district of Banjarnegara district, to further improve its performance so that the village governance system is well maintained. The data analysis technique used is test of multiple linear regression analysis. The results showed that variables of the transformational leadership style (X1) were significantly affected by the performance $(\mathrm{Y})$ variables. Then the work discipline variable (X2) significantly affects the performance variable. Variables of the transformational leadership style and work discipline are simultaneously affecting the performance variables. The working discipline variable is the variable that most affects the performance of village devices in Madukara sub-district, Banjarnegara district.
\end{abstract}

Keywords: Transformational Leadership, Work Discipline, Performance

\section{PENDAHULUAN}

Perangkat desa merupakan tingkatan pemerintahan terendah di dalam sistem pemerintahan nasional di Indonesia. Wewenang untuk mengelola kepentingan rakyatnya secara otonomi dimiliki oleh pemerintahan desa.
Undang-Undang Nomor 23 Tahun 2014 tentang Pemerintahan Daerah menegaskan bahwa pemerintahan desa diselenggarakan oleh pemerintah desa itu sendiri. Hal tersebut diperjelas di dalam Pasal 25 yang menerangkan bahwa pemerintah desa sebagaimana dimaksud 
dalam Pasal 23, adalah Kepala Desa atau yang disebut dengan nama lain dan yang dibantu oleh Perangkat Desa atau yang disebut dengan nama lain.

Dilanjutkan pada Pasal 48 yang menerangkan bahwa Perangkat desa terdiri atas sekretariat desa, pelaksana kewilayahan dan pelaksana teknis. Kepala Desa memiliki tanggung jawab dalam pelayanan publik berdasarkan kesepakatan yang dilakukan dan dipahami secara bersama. Kesepakatan tersebut telah dibahas pada kontrak politik yang terjadi pada saat kampanye, bahwa kepala desa terpilih telah berjanji atas kesediaannya sendiri untuk melayani kepentingan masyarakat desa sebagai tugas utamanya (Potabuga, 2015). Wewenang dan tugas dari kepala desa adalah untuk menyelenggarakan pemerintahan desa, melaksanakan pembangunan desa, pembinaan kemasyarakatan desa dan pemberdayaan masyarakat desa. Perangkat desa harus memiliki sumber daya manusia yang kompeten di bidangnya, sehingga dapat membantu kepala desa dalam melaksanakan tugas dalam menyelenggarakan system pemerintahan desa yang baik dan tepoat, melaksanakan pembangunan desa yang merata dan juga membina serta memberdayakan masyarakat desa.

Dalam melaksanakan tugas dan wewenangnya, perangkat desa bertanggung jawab terhadap kepala desa. Pada era reformasi sekarang ini, kinerja pemerintah mendapat sorotan tajam dari masyarakat. Dengan adanya kebebasan dalam menyampaikan pendapat (aspirasinya), banyak ditemukan kritikan yang pedas terhadap kinerja pemerintah, yang sering dikemukakan secara langsung (melalui forum resmi atau bahkan demonstrasi) maupun secara tidak langsung (melalui tulisan atau surat pembaca pada media massa).

Kritikan tersebut tanpa terkecuali mulai dari pemerintah pusat sampai ke pemerintah terendah yaitu pemerintah desa. Pentingnya sikap aparat desa dalam mewujudkan tujuan dan sasaran organisasi pemerintah tidak terlepas dari sikap dalam jiwa manusia yang sangat kuat mempengaruhi segala keputusan yang diambilnya.

Ini berarti bahwa aparat Pemerintah Desa sebagai pendukung utama penyelenggaraaan pemerintahan harus mampu menjalankan tugas dan fungsi yang diembannya.

Kecamatan Madukara merupakan salah satu kecamatan yang terletak di dalam wilayah administrasi Kabupaten Banjarnegara. Kecamatan tersebut membentang pada bagian timur Kabupaten Banjarnegara. Kecamatan tersebut berbatasan dengan Kecamatan Sigaluh di sebelah selatan, Kecamatan Banjarmangu di sebelah barat, Kecamatan Pagentan di sebelah timur dan Kabupaten Wonosobo di sebelah utara. Wilayah Kecamatan Madukara,terdiri atas 18 desa dan 2 kelurahan yang secara keseluruhan terdapat $72 \mathrm{RW}$ dan $243 \mathrm{RT}$.

Variabel ini diambil karena cocok dengan permasalahan yang terjadi pada perangkat desa di Kecamatan Madukara, Kabupaten Banjarnegara.

\section{A. Kinerja}

Kinerja berdasarkan Afrizal et al. (2014) adalah hasil yang diperoleh dari sebuah fungsi indikator pekerjaan pada suatu bidang waktu tertentu. Menurut Ma'ruf et al. (2019), Kinerja merupakan hasil berdasarkan kuantitas yang telah dilakukan dalam sebuah pekerjaan, kualitas kerja yang telah dilakukan, kerja sama yang sudah terbina selama bekerja serta layanan dan pengetahuan yang berhubungan dengan sebuah pekerjaan dalam melaksanakan pekerjaan. Hasil dari kinerja yang baik tersebut pada umumnya dapat dinilai dengan melihat taraf kehadiran karyawan, kemandirian dalam 
melakukan pekerjaan, kesetiaan kepada tempat dimana karyawan bekerja, inisiatif dalam melakukan sebuah pekerjaan, kepercayaan pada pekerjaan dan antusiasme ketika menyelesaikan pekerjaan.

Untuk menghasilkan sebuah feedback yang tepat yang mengacu kepada peningkatan produktivitas dan kinerja yang diharapkan akan lebih baik, dibutuhkan sebuah penilaian kinerja yang obyektif. Penilaian kinerja melalui metode penilaian seperti Indikator Kinerja Utama dan metode yang lain, sebenarnya mempunyai tujuan yang bertujuan untuk mengumpulkan data, menganalisa data yang diperoleh, dan menggunakan informasi / data yang ada yang bertujuan agar pekerjaan yang dilakukan lebih efisien dan efektif, serta target / tujuan kerja yang ada mampu tercapai dengan baik.

Menurut Pawirosumarto et al. (2017), Penilaian kinerja harus didasarkan kepada pemahaman tentang pengetahuan yang berhubungan dengan pekerjaan, keterampilan serta keahlian dalam melakukan sebuah pekerjaan, hingga perilaku yang seharisnya diperlukan dalam melakukan pekerjaan agar hasil yang diperoleh baik serta analisis mendalam tentang atribut dan perilaku yang dimiliki oleh seorang individu yang tentunya berhubungan dengan bagaimana individu terebut dalam melakukan sebuah pekerjaan.

Jika dinilai berdasarkan bentuk dasarnya, terdapat dua jenis kinerja yang mampu dinilai dari seorang tenaga kerja. Yang pertama adalah kinerja keseluruhan mengenai tanggung jawab teknis administratif. Kinerja ini berkaitan dengan bagaimana seorang tenaga kerja dalam melakukan perencanaan kerja, pengorganisasian kerja dan mengadministrasi sebuah pekerjaan setiap harinya melalui kemampuan teknis yang dimilikinya.

Dan yang kedua, kinerja tugas kepemimpinan, yang mana dapat dinilai baik buruknya melalui bagaimana seorang tenaga kerja dalam menetapkan tujuan strategis, menegakkan standar kinerja yang wajib dilakukan, memotivasi serta memimpin bawahan dalam menyelesaikan pekerjaan yang bisa dilakukan dengan cara memberi sebuah dorongan, pengakuan, dan kritik yang membangun (Pradhan \& Jena, 2017).

\section{B. Kepemimpinan Transformasional} Teori kepemimpinan transformasional pertama kali diperkenalkan oleh Burns (1978). Ia menggambarkan kepemimpinan transformasional sebagai sebuah metode kepemimpinan, dan bukan sebuah perilaku tertentu yang dimiliki oleh seorang pemimpin.

Sejalan dengan ide tersebut, para pemimpin transformasional merupakan individu-individu yang tertarik kepada cita-cita dan nilai-nilai etis yang lebih tinggi dan mampu untuk memberdayakan bawahannya dalam menghasilkan perubahan yang mendalam dan mendasar.

Teori

kepemimpinan transformasional merupakan salah satu teori kepemimpinan yang paling dominan dan banyak dijadikan topik penelitian dalam tiga dekade terakhir (Mhatre \& Riggio, 2014).

Sedangkan menurut GarcíaMorales et al. (2012), seorang individu yang memiliki gaya kepemimpinan transformasional mampu memberikan inspirasi dengan memotivasi pengikut mereka, sebagian besar melalui komunikasi yang baik dan mempunyai tingkat pengharapan yang tinggi kepada bawahannya. Pemimpin 
transformasional tidak hanya mampu mempengaruhi semua bawahannya, tetapi juga mampu memberikan pengaruhnya kepada tim dan organisasi mereka untuk meningkatkan kinerjanya (Wang, Oh, Courtright, \& Colbert, 2011).

Suatu model kepemimpinan yang bersifat positif memfokuskan kepada perilaku yang dimiliki oleh seorang pemimpin dan focus kepada dinamika interpersonal yang mampu meningkatkan kepercayaan diri yan dimiliki oleh bawahan dan menghasilkan hasil positif, di luar kepatuhan tugas, seperti memotivasi bawahan untuk melampaui ekspektasi yang ada, sebagai motivasi pengembangan diri kea rah yang positif, dan perilaku individu yang pro-sosial (Hannah, Sumanth, Lester, \& Cavarretta, 2014).

\section{Disiplin Kerja}

Disiplin kerja memainkan merupakan hal yang penting yang harus dimiliki tenaga kerja di dalam melaksanaan pekerjaan mereka sehari-hari. Seorang individu yang mempunyai tingkat kedisiplinan yang tinggi akan tetap bekerja dengan baik walaupun tanpa diawasi oleh pengawas. Mereka yang mempunyai tingkat kedisiplinan yang tinggi tidak akan melakukan hal-hal lain yang tidak ada hubungannya dengan pekerjaan yang mereka lakukan. Dapat disimpulkan pula bahwa mereka yang disiplin kerjanya tinggi akan memiliki kinerja yang baik apabila dibandingkan dengan mereka yang malas, karena waktu kerja yang mereka gunakan untuk bekerja sesuai dengan target (Hersona \& Sidharta, 2017). Tingkat kedisiplinan seorang tenaga kerja menurut Dapu (2015) dapat dilihat dari tanggung jawab, sikap, perilaku dan tindakan seorang karyawan sesuai dengan semua bentuk peraturan selama mereka bekerja. Disiplin adalah modal yang dibutuhkan dalam mencapai tujuan yang diinginkan. Harlie (2010) menyatakan secara alami, kesadaran diri di antara individu dalam disiplin kerja harus dikembangkan untuk menyelesaikan tugas yang diberikan oleh organisasi melalui pengembangan motivasi dan komitmen orang-orang dalam organisasi.

Menurut Simatupang \& Saroyeni (2018) dalam penelitiannya, keberadaan disiplin kerja diperlukan dalam suatu lembaga atau organisasi, karena dalam suasana disiplin suatu lembaga atau organisasi akan dapat mengimplementasikan program kerjanya untuk mencapai target yang ditetapkan.

Tujuan utama dari disiplin adalah untuk meningkatkan efisiensi sebanyak mungkin dengan mencegah dan memperbaiki tindakan individu diperlukan untuk mendukung kelancaran semua kegiatan organisasi untuk mencapai tujuan maksimal.

\section{METODE PENELITIAN}

Jenis penelitian yang digunakan merupakan penelitian dengan metode kuantitatif. Pengumpulan data dilakukan dengan menyebar kuesioner yang dibagikan kepada 173 orang perangkat desa yang ada pada Kecamatan Madukara, Kabupaten Banjarnegara. Setelah Kuesioner terkumpul kemudian dilakukan Uji Validitas dan Reabilitas untuk menguji apakah data yang dihasilkan bersifat valid dan reliabel. Kemudian dilakukan Uji Asumsi Klasik untuk menguji apakah data bersifat normal dan apakah terdapat gejala multikolinieritas serta terbebas dari asumsi heteroskedastisitas. Setelah semua data dinyatakan mampu digunakan sebagai bahan uji maka kemudian 
dilakukan Uji Analisis Regresi Linier Berganda.

Kinerja seorang tenaga kerja dinilai dari bagaimana ia menyelesaikan pekerjaan yang telah diberikan, bagaimana ia mampu memenuhi tenggat waktu yang diberikan, bagaimana kompetensi yang ia miliki serta potensi yang mampu ia tunjukkan dalam melakukan sebuah pekerjaan. Beberapa masalah yang sering timbul, yang berhubungan dengan inovasi yang buruk, produktivitas tenaga kerja yang rendah, ketidakmampuan dalam memenuhi target kinerja yang telah diberikan, jika dibiarkan terus menerus, tentunya akan mampu mempengaruhi kinerja secara keseluruhan (Iqbal et al., 2015).

Bagaimana seorang pemimpin berupaya dalam memenuhi kebutuhan pengikut-pengikutnya, digambarkan melalui gaya kepemimpinan model transformasional. Menurut Judge \& Piccolo (2004), Dimensi-dimensi gaya kepemimpinan transformasional tergambarkan pada empat pengaruh yang mampu diberikan seorang pimpinan kepada bawahannya, yaitu (1) Pengaruh Ideal (2) Motivasi Inspirasional (3) Stimulasi Intelektual (4) Pertimbangan Individual.

Agustini (2011) dalam penelitiannya mengemukakan beberapa indikator disiplin kerja yang ada yaitu (1) Tingkat Kehadiran (2) Prosedur Kerja (3) Kepatuhan Pada Kepemimpinan (4) Kesadaran Kerja (5) Tanggung Jawab.

\section{HASIL DAN PEMBAHASAN}

A. Uji Validitas dan Reliabilitas
Uji Validitas dilakukan dengan membandingkan antara korelasi validitas r-hitung dengan nilai $r$-table untuk degree of freedom $(\mathrm{df})=\mathrm{n}-2(123-2=121)$ sehingga didapatkan angka sebesar 0,1771. Ketiga variabel yang digunakan dalam penelitian ini dinyatakan valid. Hasil uji validitas menunjukkan

bahwa nilai r-hitung milik ketiga variabel ini lebih besar dibandingkan dengan r-tabel (0,1771). Uji Reliabilitas nilai Cronbach's Alpha dari ketiga variable yang digunakan dalam penelitian ini menunjukkan bahwa nilainya $>0,60$. Hal tersebut menunjukkan bahwa kuesioner yang digunakan dalam penelitian ini dapat dikatakan reliabel atau handal, jika jawaban seseorang terhadap pernyataan adalah konsisten dan stabil dari waktu ke waktu. Hasil dari sebuah Uji Reliabilitas dapat dikatakan reliabel apabila nilai Cronbach's Alpha pada seluruh variabel $>0,60$ (Sujarweni, 2015).

\section{B. Uji Asumsi Klasik}

1. Normalitas

Berdasarkan pada hasil output SPSS uji One-Sample Kolmogorov Smirnov, nilai Asymptotic Significant yang ditunjukkan adalah sebesar 0,200. Kesimpulan yang dapat diperoleh bahwa data unstandardized residual yang ada sudah terdistribusi normal, karena Asymptotic Significant lebih dari 0,05 .

\section{Multikolinieritas}

Suatu model regresi dapat dikatakan bebas multikolineritas dengan melihat apabila nilai VIF $<10$ dan mempunyai angka tolerance $>0,10$. Berdasarkan hasil analisis yang telah dilakukan, diperoleh nilai tolerance dari masing-masing variabel $>0,10$. Nilai tolerance variabel Gaya Kepemimpinan Transformasional $=0,727$. Sementara untuk Disiplin Kerja = 0,582. Nilai VIF pada masingmasing variabel pun semuanya $<$ 10 (nilai VIF Gaya Kepemimpinan Transformasional 
$=1,376$ dan Disiplin Kerja $=$ 1,718). Maka dapat disimpulkan bahwa data penelitian ini terbebas dari gejala multikolinieritas.

3. Heteroskedastisitas

Uji Heteroskedastisitas dilakukan dengan metode glejser, yang dilakukan dengan melakukan regresi variabel bebas terhadap nilai absolut residualnya. Apabila data hasil regresi menunjukan nilai signifikansi > $(0,05)$, maka data dapat dinyatakan terbebas dari asumsi Heteroskedastisitas atau tidak adanya kesaman variance dari residual satu pengamatan ke pengamatan lain.

Nilai signifikansi variabel gaya kepemimpinan transformasional menunjukkan angka sebesar 0,511 sementara untuk variabel disiplin kerja menunjukkan angka sebesar 0,503. Dapat disimpulkan bahwa tidak ada variable yang nilai signifikansinya $<0,05$. Kesimpulan akhirnya, model regresi terbebas dari heteroskedastisitas karena nilai signifikan $>0,05$.

\section{Uji Regresi}

1. Analisis Regresi Linier Berganda Analisis regresi linier berganda digunakan untuk menganalisa bagaimana pengaruh kedua variabel independent terhadap variabel dependen yang ada. Dalam penelitian ini variabel independennya adalah Gaya Kepemimpinan Transformasional (X1) dan Disiplin Kerja (X2), serta variable dependennya adalah Kinerja (Y). Hasil uji regresi linier berganda dapat dilihat dalam tabel berikut ini:

Tabel 1. Hasil Analisis Regresi Linier Berganda

Coefficients $^{\mathrm{a}}$

\begin{tabular}{|l|c|c|c|c|c|}
\hline \multirow{2}{*}{ Model } & \multicolumn{2}{|c|}{$\begin{array}{c}\text { Unstandardized } \\
\text { Coefficients }\end{array}$} & $\begin{array}{c}\text { Standardized } \\
\text { Coefficients }\end{array}$ & & \\
\cline { 2 - 4 } & B & $\begin{array}{c}\text { Std. } \\
\text { Error }\end{array}$ & Beta & T & Sig. \\
\hline $1 \quad$ Constant) & 2,202 &, 128 &, 261 & 17,185 &, 000 \\
$\quad$ Gaya &, 33 &, 030 & 4,493 &, 000 \\
$\quad \begin{array}{l}\text { Kepemimpinan } \\
\quad \text { Transformasional } \\
\quad \text { Disiplin_Kerja }\end{array}$ &, 186 &, 033 &, 362 & 5,573 &, 000 \\
\hline
\end{tabular}

a. Dependent Variable: Kinerja_Perangkat

Sumber: Diolah Peneliti (2019)

Berdasarkan hasil analisis regresi di atas, dapat disusun persamaan regresi sebagai berikut:

$$
\begin{aligned}
\mathrm{Y} & =\alpha+\beta 1 \mathrm{X} 1+\beta 2 \mathrm{X} 2+\mathrm{e} \\
& =2,202+0,133 \mathrm{X}_{1}+0,186 \mathrm{X}_{2}+\mathrm{e}
\end{aligned}
$$

Persamaan regresi diatas dapat dijelaskan sebagai berikut: Nilai konstanta $(\alpha)$ menunjukkan 2,202 artinya apabila Gaya Kepemimpinan Transformasional dan Disiplin Kerja bernilai nol atau tidak ada perubahan, maka Kinerja 
Perangkat Desa bernilai sebesar 2,202 satuan.

$\beta 1=0,133$ mempunyai arti bahwa setiap terjadi peningkatan Gaya Kepemimpinan Transformasional kerja sebesar 1 satuan, maka akan terjadi kenaikan Kinerja Perangkat sebesar 0,133 satuan dengan asumsi variabel independent yang lain tetap.

$\beta 2=0,186$ mempunyai arti bahwa setiap terjadi peningkatan Disiplin Kerja sebesar 1 satuan, maka akan terjadi kenaikan Kinerja Perangkat sebesar 0,186 satuan dengan asumsi variabel independent yang lain tetap.

$\mathrm{e}=$ Standar kesalahan (error).

\section{Uji Determinasi}

Dari tabel di atas dapat dilihat bahwa Nilai Adjusted $R$ square dari model regresi yang terbentuk dalam penelitian ini adalah sebesar 0,700 yang menunjukkan bahwa variabel independent (Gaya Kepemimpinan Transformasional dan Disiplin Kerja) dalam menjelaskan variabel dependent (Kinerja Perangkat) adalah sebesar $70 \%$, yang mana sisanya sebesar $30 \%$ dijelaskan oleh variabel lain yang tidak dimasukkan dalam penelitian ini.

\section{Pengujian Hipotesis}

1. Uji f (Simultan)

Dari Uji ANOVA, nilai fhitung $>$ f-tabel adalah 95,943 > 2,68 dengan tingkat signifikansi 0,000 . Karena probabilitas $(0,000)$ jauh lebih kecil dari 0,05 maka model regresi uji-f dapat digunakan untuk memprediksi kinerja perangkat desa. Berdasarkan Analisis tersebut dapat dikatakan bahwa Gaya Kepemimpinan Transformasional dan Disiplin Kerja berpengaruh secara simultan terhadap Kinerja Perangkat Desa pada Kecamatan Madukara Banjarnegara sehingga hipotesis diterima.

2. Uji t (Parsial)

Untuk menguji pengaruh Gaya Kepemimpinan Transformasional dan Disiplin Kerja secara parsial terhadap Kinerja Perangkat Desa adalah dengan menggunakan tabel $t$. Hasil uji-t menunjukkan bahwa variabel Gaya Kepemimpinan Transformasional memiliki nilai thitung sebesar 4,493 yang mana lebih besar dari nilai t-tabel sebesar 1,97993 dengan nilai signifikansi $<0,05$ yaitu 0,000 . Sehingga dapat disimpulkan bahwa terdapat pengaruh antara Gaya Kepemimpinan Transformasional terhadap Kinerja Perangkat Desa, sehingga hipotesis diterima dan $\mathbf{H}_{0}$ ditolak.

Hal tersebut sejalan dengan hasil penelitian yang dilakukan oleh Birasnav (2014) yang menyatakan bahwa Gaya Kepemimpinan Transformasional berpengaruh signifikan terhadap Kinerja sumber daya manusia. Hasil penelitian lain yang sejalan juga dikemukakan oleh penelitian Nunik et al. (2018) juga menyatakan bahwa Gaya Kepemimpinan Transformasional berpengaruh signifikan terhadap kinerja karyawan PT. Kimia Farma (Persero) Tbk dan PT. Bio Farma (Persero).

Sementara itu untuk variabel Disiplin Kerja, Hasil uji-t menunjukkan bahwa nilai t-hitung sebesar 5,573 yang mana lebih besar dari nilai t-tabel sebesar 1,97993 dengan nilai signifikansi $<0,05$ yaitu 0,000 . Sehingga dapat 
disimpulkan bahwa terdapat pengaruh antara Disiplin Kerja terhadap Kinerja Perangkat Desa, sehingga hipotesis diterima dan $\mathrm{H}_{\mathrm{o}}$ ditolak.

Hal tersebut sejalan dengan hasil penelitian yang dilakukan oleh Simatupang \& Saroyeni (2018) yang menyatakan bahwa Disiplin Kerja berpengaruh signifikan terhadap Kinerja karyawan di Biro Administrasi Umum rektorat Universitas Cenderawasih. Hasil penelitian lain yang sejalan juga dikemukakan oleh dengan penelitian Rachmawati \& Mauludin (2018), yang juga menyatakan bahwa Disiplin Kerja berpengaruh signifikan terhadap Kinerja aparatur sipil negara Kabupaten Pasuruan.

\section{KESIMPULAN}

Berdasarkan analisis data dan pembahasan yang telah dilakukan, maka dapat ditarik kesimpulan bahwa Gaya Kepemimpinan Transformasional dan Disiplin Kerja berpengaruh signifikan terhadap kinerja karyawan.

Disiplin Kerja memiliki pengaruh yang paling besar terhadap Kinerja Perangkat Desa. Karena dengan disiplin yang baik, dengan mengikuti aturan yang ada, tenaga kerja dapat melakukan tugasnya tepat waktu dan tidak menghalangi bidang kerja lain dalam satu tempat kerja yang sama. Selain itu, perangkat desa di Kecamatan Mandiraja Kabupaten Banjarnegara juga memiliki disiplin kerja yang tinggi. Hal ini dibuktikan dengan rendahnya tingkat absensi. Dapat disimpulkan bahwa tingkat kesadaran kerja perangkat desa Kecamatan Madukara Kabupaten Banjarnegara sudah lumayan tinggi untuk ukuran aparatur sipil negara.

Ada beberapa keterbatasan yang ada pada penelitian ini. Sampel yang digunakan dalam penelitian ini adalah sebesar 173 responden, dan data yang dapat dianalisis sebanyak 173 responden, sehingga tidak menutup kemungkinan akan diperoleh hasil yang berbeda jika menggunakan sampel yang lebih banyak.

Metode pengumpulan data primer dilakukan hanya melalui media kuesioner, sehingga kesimpulan yang dikemukakan hanya berdasarkan pada data yang terkumpul melalui instrumen secara tertulis. Perlu dikakukan wawancara agar hasil yang diperoleh lebih obyektif.

Hasil dari penelitian ini memiliki sejumlah saran terutama untuk para perangkat desa khususnya di Kecamatan Madukara Kabupaten Banjarnegara, agar lebih meningkatkan kinerjanya supaya sistem pemerintahan desa tersselenggara dengan baik. Saran bagi penelitian dimasa akan datang adalah sebaiknya menggunakan variabel independent yang bervariasi seperti kompensasi, motivasi, iklim organisasi, budaya organisasi. Sehingga dapat melakukan penelitian kembali dengan objek yang lain untuk mendapatkan generalisasi hasil penelitian.

\section{DAFTAR PUSTAKA}

Afrizal, P.R., Al Musadieq, M., Ruhana, I. (2014). Pengaruh konflik kerja dan stres kerja terhadap kepuasan kerja (Studi pada Karyawan PT. TASPEN (PERSERO) Cabang Malang), Jurnal Administrasi Bisnis, 8, 1-10.

Agustini, Fauzia. (2011). Advanced Human Resource Management, the first edition. Medan: Publisher Madenatera.

Birasnav, M. (2014). Knowledge management and organizational performance in the service industry: The role of transformational leadership beyond the effects of transactional leadership. Journal of Business Research, 67(8), 1622- 
(ISSN Cetak 1978-6573) (ISSN Online 2477-300X)

1629.https://doi.org/10.1016/j.jbusres .2013 .09 .006

Burns, J.M. (1978). Leadership, Harper \& Row. New York, NY.

Dapu, Valensia A.W. (2015). The Influence of Work Discipline, Leadership, and Motivation on Employee Performance at PT. Trakindo Utama Manado. Jurnal Riset Ekonomi, Manajemen, Bisnis Dan Akuntansi, 3(3), 352-361.

García-Morales, V.J., JiménezBarrionuevo, M.M., \& GutiérrezGutiérrez, L. (2012). Transformational leadership influence on organizational performance through organizational learning and innovation. Journal of Business Research, 65(7), 10401050.

https://doi.org/10.1016/j.jbusres.2011 .03 .005

Hannah, S.T., Sumanth, J. J., Lester, P., \& Cavarretta, F. (2014). Debunking the false dichotomy of leadership idealism and pragmatism: Critical evaluation and support of newer genre leadership theories. Journal of Organizational Behaviour, 35: 598621.

Harlie, M. (2010). Pengaruh Disiplin Kerja, Motivasi, Dan Pengembangan Karir Terhadap Kinerja Pegawai Negeri Sipil Pada Pemerintah Kabupaten Tabalong di Tanjung Kalimantan Selatan. Jurnal Manajemen, 11(2).

Hersona, S., \& Sidharta, I. (2017). Motivation and Work Discipline on Employees' Performance. Jurnal Aplikasi Manajemen, 15(3), 528537.

Iqbal N, Anwar S, H.N. (2015). Effect of Leadership Style on Employee Performance. Arabian Journal of Business and Management Review, 5(5), $1-6$. https://doi.org/10.4172/2223$\underline{5833.1000146}$
Judge, T.A., \& Piccolo, R.F. (2004). Transformational and transactional leadership: A meta-analytic test of their relative validity. Journal of Applied Psychology, 89, 755-768. http://dx.doi.org/10.1037/0021$\underline{9010.89 .5 .755}$

Ma'ruf, F., Hadari, I.R., \& Amalia, D. (2019). Employee Motivation and Performance Models. International Review of Management and Marketing, 9(6), 80-86. https://doi.org/10.32479/irmm.8811

Mhatre, K. H., \& Riggio, R. E. (2014). Charismatic and transformational leadership: Past, present, and future. The Oxford Handbook of Leadership and Organizations, 221-240.

Nunik, L.D., Yuliana Gunawan, S.A.V. (2018). Organizational citizenship behaviour. SOSIO DIDAKTIKA: Social Science Education Journal, 5(1). https://doi.org/10.1108/ijoa-082012-0586

Pawirosumarto, S., Sarjana, P.K., \& Muchtar, M. (2017). Factors affecting employee performance of PT. Kiyokuni Indonesia. International Journal of Law and Management, 59(4), 602-614. https://doi.org/10.1108/IJLMA-032016-0031

Pradhan, R.K., \& Jena, L.K. (2017). Employee Performance at Workplace: Conceptual Model and Empirical Validation. Business Perspectives and Research, 5(1), 6985.

https://doi.org/10.1177/22785337166 71630

Potabuga, J. (2015). Peranan Kepala Desa Dalam Pelayanan Publik (Studi Di Desa Pontak Kabupaten Minahasa Selatan). E-Journal "Acta Diurna", 4(2).

Rachmawati, D., \& Mauludin, H. (2018). The Effect of Work Discipline and Job Involvement on the Performance 
with Incentive as Intervening Variable. 7(8), 21-30.

Simatupang, A., \& Saroyeni, P. (2018). The Effect of Discipline, Motivation and Commitment to Employee Performance. IOSR Journal of Business and Management (IOSRJBM), 20(6), 31-37. https://doi.org/10.9790/487X2006013137

Sujarweni. (2015). Metodologi Penelitian - Bisnis \& Ekonomi. Yogyakarta: Pustaka baru press.

Wang, G., Oh, I.S., Courtright, S.H., \& Colbert, A.E.. (2011). Transformational leadership and performance across criteria and levels: A meta-analytic review of 25 years of research. Group and Organization Management, 36(2), 223-270.

https://doi.org/10.1177/10596011114 $\underline{01017}$ 